\title{
Transmission rates of the bacterial endosymbiont, Neorickettsia risticii, during the asexual reproduction phase of its digenean host, Plagiorchis elegans, within naturally infected lymnaeid snails
}

\author{
Stephen E Greiman *, Vasyl V Tkach and Jefferson A Vaughan
}

\begin{abstract}
Background: Neorickettsia are obligate intracellular bacterial endosymbionts of digenean parasites present in all lifestages of digeneans. Quantitative information on the transmission of neorickettsial endosymbionts throughout the complex life cycles of digeneans is lacking. This study quantified the transmission of Neorickettsia during the asexual reproductive phase of a digenean parasite, Plagiorchis elegans, developing within naturally parasitized lymnaeid pond snails.

Methods: Lymnaea stagnalis snails were collected from 3 ponds in Nelson County, North Dakota and screened for the presence of digenean cercariae. Cercariae were identified to species by PCR and sequencing of the 28S rRNA gene. Neorickettsia infections were initially detected using nested PCR and sequencing of a partial 16S rRNA gene of pooled cercariae shed from each parasitized snail. Fifty to 100 single cercariae or sporocysts were isolated from each of six parasitized snails and tested for the presence of Neorickettsia using nested PCR to estimate the efficiency at which Neorickettsia were transmitted to cercariae during asexual development of the digenean.

Results: A total of 616 L. stagnalis were collected and 240 (39\%) shed digenean cercariae. Of these, 18 (8\%) were Neorickettsia-positive. Six Neorickettsia infections were selected to determine the transmission efficiency of Neorickettsia from mother to daughter sporocyst and from daughter sporocyst to cercaria. The prevalence of neorickettsiae in cercariae varied from 11 to $91 \%$. The prevalence of neorickettsiae in sporocysts from one snail was $100 \%$.

Conclusion: Prevalence of Neorickettsia infection in cercariae of Plagiorchis elegans was variable and never reached $100 \%$. Reasons for this are speculative, however, the low prevalence of Neorickettsia observed in some of our samples (11 to 52\%) differs from the high prevalence of other, related bacterial endosymbionts, e.g. Wolbachia in Wolbachia-dependent filariid nematodes, where the prevalence among progeny is universally $100 \%$. This suggests that, unlike the Wolbachia-filaria relationship, the Neorickettsia-digenean relationship is not obligatory mutualism. Our study represents the first quantitative estimate of the Neorickettsia transmission through the asexual phase of the digenean life cycle.
\end{abstract}

Keywords: Neorickettsia, Digenean, Transmission, Cercariae, Sporocysts

\footnotetext{
* Correspondence: stephen.greiman@my.und.edu

Department of Biology, University of North Dakota, 10 Cornell St., Grand

Forks, North Dakota 58202, USA
}

\section{Biomed Central}

(c) 2013 Greiman et al.; licensee BioMed Central Ltd. This is an open access article distributed under the terms of the Creative Commons Attribution License (http://creativecommons.org/licenses/by/2.0), which permits unrestricted use, distribution, and reproduction in any medium, provided the original work is properly cited. 


\section{Background}

Bacteria in the genus Neorickettsia (Order Rickettsiales, Family Anaplasmataceae) are intracellular endosymbionts of digeneans. Neorickettsiae are presumably maintained throughout the digenean life cycle by vertical transmission during the sexual and asexual reproductive phases of the parasite. Digeneans are endoparasitic flatworms with complex life cycles involving asexual reproduction in mollusks (=first intermediate host) and sexual reproduction in vertebrates (=definitive host) (Figure 1 ). In some cases neorickettsiae are transmitted horizontally from digeneans to their vertebrate definitive hosts, where the bacteria can infect white blood cells and cause debilitating disease in horses, dogs, and humans [1-6]. Currently, Neorickettsia comprises three named species and several unnamed species level lineages [6,7].

Neorickettsia risticii is the most widespread member of the genus in the United States and worldwide [1,7-11]; for detailed review see [6]. It is known to cause a horse illness called equine monocytic ehrlichiosis or Potomac horse fever referring to the region where it was first discovered. Its clinical symptoms vary and usually include fever, depression, anorexia and colitis, accompanied by acute diarrhea $[1,10]$. If untreated the disease causes abortions in pregnant mares and relatively high mortality approaching 30\% [12,13]. Due to the fact that $N$. risticii was initially placed in the genus Ehrlichia, the disease was first thought to be transmitted by ticks. However, as a result of combined molecular and experimental approaches it was demonstrated to be associated with digeneans [14-18]. Since then, $N$. risticii was detected in representatives of several digenean families, e. g., Lecithodendriidae, Plagiorchiidae, Microphallidae, Macroderoididae, and Echinostomatidae [7,17-25]. Although the digenean hosts of $N$. risticii have diverse life cycles that utilize various groups of invertebrates and even vertebrate intermediate hosts, it has been shown that amphibiotic insects such as mayflies and caddisflies play a particularly important role in the epizootology of Potomac horse fever [20,22,26]. When horses swallow insects infected by metacercariae harboring Neorickettsia, they may develop Potomac horse fever even though the digeneans cannot develop to adult stages in horses.

Despite their role as pathogens of humans, domestic animals and wildlife, practically no quantitative information exists concerning the transmission of Neorickettsia through the digenean life cycle. Gibson et al. [23] used immunofluorescence and PCR to demonstrate vertical transmission of $N$. risticii from the adult digenean Acanthatrium oregonense to its eggs and horizontal transmission of bacteria from the digeneans to their bat host. These authors randomly removed 5 individual eggs from each of two bats and screened them for $N$. risticii by PCR. Seven out of 10 eggs were positive for Neorickettsia, however, it was unclear whether each set of eggs originated from a single worm.

Ability to pass and reproduce through both sexual and asexual phases of the digenean life cycle is essential to

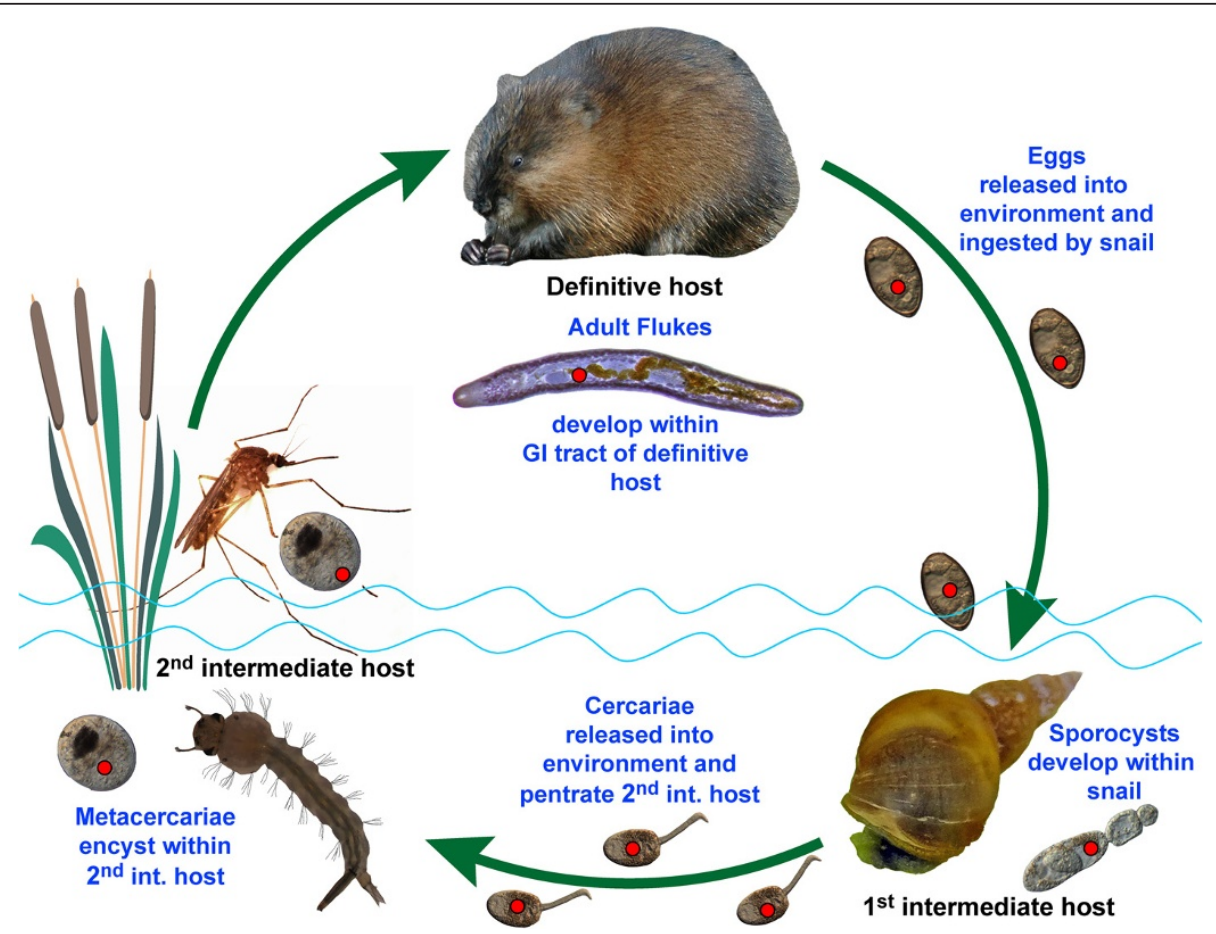

Figure 1 Natural life cycle of the digenean Plagiorchis elegans. Neorickettsia infection is represented by a red dot. 
the perpetuation of Neorickettsia in nature. This study reports the prevalence of Neorickettsia endosymbionts in cercariae (i.e., progeny of digenean asexual stages) of the digenean Plagiorchis elegans (family Plagiorchiidae) shed by naturally-parasitized pond snails Lymnea stagnalis collected in eastern North Dakota. P. elegans has a life cycle typical for the Plagiorchiidae that involves an aquatic snail (in this case Lymnaea stagnalis) as the first intermediate host, an arthropod as the second intermediate host and a vertebrate as the definitive host (Figure 1). After eggs are laid by an adult worm they are shed with host feces to the external environment. In water, eggs undergo embryonation and need to be ingested by a snail. The next stage, miracidium, hatches in the intestine of the snail, penetrates through the intestinal wall, reaches the hepatopancreas of the mollusk and develops into a mother sporocyst. The mother sporocyst goes through multiple rounds of asexual reproduction, producing a large number of daughter sporocysts. The daughter sporocysts produce a large number of the next stage, cercariae, through asexual reproduction. Cercariae are shed by the mollusk into the aquatic environment where they may penetrate an aquatic arthropod and encyst to form metacercaria. After some development, the metacercaria needs to be swallowed by an appropriate vertebrate host to mature into adult stage (Figure 1).

To the best of our knowledge, these data represent the first quantitative estimates of infection rates for Neorickettsia endosymbionts during the asexual reproductive phase of digenean parasites.

\section{Methods}

Lymnaea stagnalis snails were collected during the summer months of 2011-2012 from 3 ponds in Nelson County, North Dakota; Pond 1 (Lat: $48^{\circ} 0^{\prime} 24.18^{\prime \prime} \mathrm{N}$ and Long: $\left.97^{\circ} 56^{\prime} 37.32^{\prime \prime} \mathrm{W}\right)$, Pond $2\left(48^{\circ} 1^{\prime} 43.80^{\prime \prime} \mathrm{N}, 97^{\circ} 59^{\prime}\right.$ $\left.24.88^{\prime \prime} \mathrm{W}\right)$, Pond $3\left(48^{\circ} 10^{\prime} 48.60^{\prime \prime} \mathrm{N}, 98^{\circ} 7^{\prime} 51.29^{\prime \prime} \mathrm{W}\right)$. Snails were rinsed with water and placed individually into glass jars filled with aged tap water treated with commercial aquarium conditioner to remove chlorine/ chloramines. Snails were kept for several hours under fluorescent lamps followed by several hours without light. Afterwards, the water in jars was examined for the presence of cercariae. Snails shedding cercariae were maintained individually in labeled containers and fed with lettuce.

Initial screening for Neorickettsia was carried out using pooled cercariae. Fifty cercariae from each shedding snail were pipetted into a $1.75 \mathrm{ml}$ microcentrifuge tube and centrifuged at 13,000 rpm for five minutes. Supernatant was removed and $75 \mu \mathrm{l}$ of ultrapure water added. Cercariae were disrupted by direct sonication using a UP100H compact ultrasonic processor (Hielscher USA, Inc., Ringwood, NJ) at an amplitude of $70 \%$ for 15 seconds, and immediately placed on ice to prevent DNA degradation due to enzymatic activity. Sonicates were used directly as a template for PCR amplification procedures. DNA was extracted from the remainder of each homogenate using the guanidine thiocyanate method [27] and used for the digenean taxon identification.

If Neorickettsia was detected in pooled cercariae from an individual snail, 50 or 100 individual cercariae or sporocysts from that snail were tested for Neorickettsia. One of the snails with Neorickettsia-positive digenean infection was dissected for individual screening of both sporocysts and cercariae. Individual sporocysts were carefully separated using very fine needles under high power of a stereo microscope. A single cercaria or sporocyst was placed in $50 \mu \mathrm{l}$ of ultrapure water and disrupted by direct sonication as described above. We did not detect any PCR inhibition with either pooled cercarial or single cercarial/sporocyst sonicates.

To validate the use of sonication as a method of obtaining DNA from single cercariae, 26 single cercariae were sonicated, screened for neorickettsial DNA using a nested PCR protocol as well as for digenean DNA using digenean-specific primers with a standard PCR protocol. All sonicates produced good amplicons of digenean DNA indicating that sonication of single cercariae yielded sufficient quantity and quality of DNA for use in PCR (Figure 2).

Sonicates were assayed for $N$. risticii using a substantially modified nested PCR protocol initially described by Barlough et al. [28]. Five microliters of each sonicate were used for the first PCR reaction and $1 \mu \mathrm{l}$ (pooled cercariae) or $3 \mu \mathrm{l}$ (single cercariae/sporocysts) of the first PCR product were used for the nested PCR. The nested PCR amplified a 527-bp portion of the 5" end of the 16S rRNA gene. The primer pairs (designed by SEG) used in the first round were n16S-25 F (5'-TCAGAACGAACGCTAGCGGT-3') and n16S-610R (5'-GACGTTCCTCTTGATATCTACG$\left.3^{\prime}\right)$. Primers used in the nested PCR round were n16S-70 F (5'-GAATCAGGGCTGCTTGCA-3'; designed by SEG) and ER2-R (5'-GTTTTAAATGCAGTTCTTGG-3' from Barlough et al. [28]).

The PCR reactions were run on an EP Gradient thermocycler (Eppendorf, Hauppauge, NY) using Quick load OneTaq mastermix (New England Biolabs, Ipswich, MA) according to the manufacturer's instructions. Annealing temperature of $54^{\circ} \mathrm{C}$ and 40 cycles were used in both initial and nested PCRs. DNA extracts of $N$. risticii were used as positive controls (graciously provided by Dr. John Madigan, UC Davis). In negative controls, ultrapure water was used in place of sonicates.

Digenean cercariae were identified to species using partial sequences of the $28 \mathrm{~S}$ rRNA gene. Digenean DNA was amplified by PCR using forward primer digl2 (5'-AAGCATATCACTAAGCGG-3') and reverse primer 

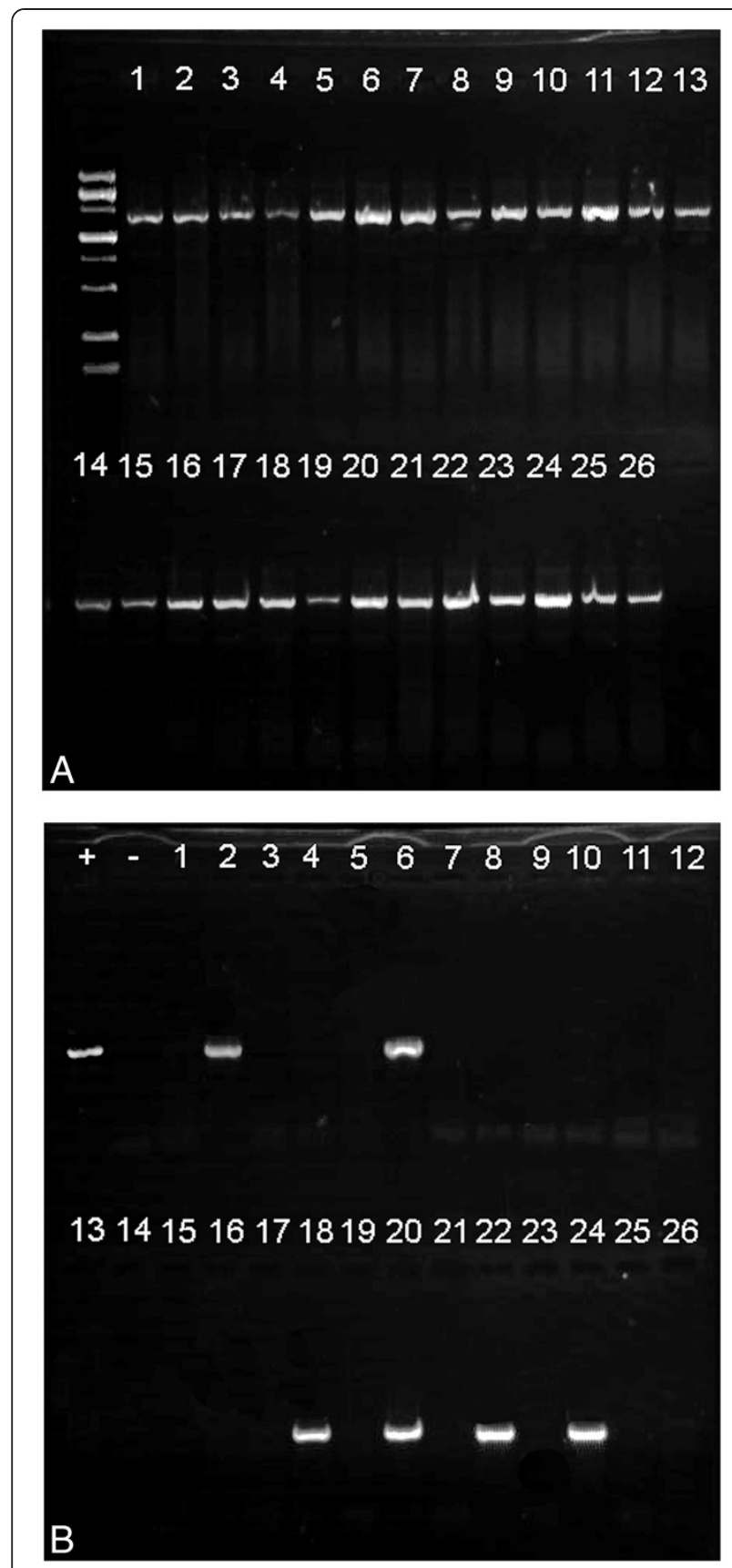

Figure 2 Electrophoregrams showing results of PCR of bacterial and digenean DNA from the same extracts obtained from single cercariae. (A) Results of amplification of digenean partial $28 \mathrm{~S}$ gene from 26 single cercarial homogenates. (B) Results of screening the same 26 single cercarial homogenates for Neorickettsia DNA by nested PCR of partial 165 gene. Lanes with positive and negative controls are labeled.

1500R (5'-GCTATCCTGAGGGAAACTTCG-3') designed by VVT.

PCR amplicons of both Neorickettsia and digeneans were purified using either the DNA Clean \& Concentrator $^{\text {Tix }}-5$ kit (Zymo Research, Irvine, CA) or ExoSap PCR clean-up enzymatic kit (Affimetrix, Santa Clara, CA), according to the manufacturers' instructions. The PCR products were cycle-sequenced using ABI BigDye ${ }^{\mathrm{Tx}}$ chemistry, alcohol precipitated and run on an ABI Prism $3100^{\mathrm{mm}}$ automated capillary sequencer. PCR products were sequenced in both directions. For sequencing of Neorickettsia, nested PCR primers were used. For sequencing of cercariae, the PCR primers as well as internal forward primers $300 \mathrm{~F}$ (5' -CAAGTACCGTGAGGGAAAGTTG-3'), 900 F (5' CCGTCTTGAAACACGGACCAAG- $3^{\prime}$ ) and internal reverse primers 300R (5'-CAACTTTCCCTCACGGT ACTTG-3') and ECD2 (5' -CTTGGTCCGTGTTTCAA GACGGG-3') were used. Contiguous sequences of Neorickettsia and cercariae/sporocysts were assembled and edited using Sequencher ${ }^{\mathrm{mn}}$ ver. 4.2 (GeneCodes Corp., Ann Arbor, MI) and submitted to GenBank under accession numbers: Plagiorchis elegans [GenBank: KF556678] and Neorickettsia risticii [GenBank: KF556679].

\section{Results}

Out of 616 L. stagnalis collected in all three ponds, 240 shed digenean cercariae (Table 1). Eighteen (8\%) of the 240 cercarial infections were Neorickettsia-positive. Prevalences of Neorickettisia in single cercariae and sporocysts were only studied from Pond 2 . This pond had the highest prevalence of Neorickettsia (23\%) in digeneans, although not the highest prevalence of digeneans in snails (Table 1). Using DNA sequencing, we were able to identify both the digenean and the neorickettsial endosymbiont. All Neorickettsia-positive infections represented a single digenean species, a plagiorchiid Plagiorchis elegans. Sequences of cercariae were identical to the sequence of adult $P$. elegans from the same area published by Tkach et al. [7].

We used 5 P. elegans infections for analysis of the efficiency of Neorickettsia transmission through the asexual stage of the digenean life cycle. All 5 samples of P. elegans harbored Neorickettsia risticii, the agent of the Potomac horse fever. The prevalence of individually screened cercariae infected with Neorickettsia varied from 11\% to 91\% among the 5 digenean samples (Table 2). Fifty sporocysts and 50 cercariae were screened from one of the snails. In this case, all sporocysts assayed were positive for

Table 1 Infection prevalences for digeneans in snails and Neorickettsia in digeneans in Nelson Co., North Dakota

\begin{tabular}{ccc}
\hline & $\begin{array}{c}\text { Prevalence of } \\
\text { digeneans }=\% \\
\text { in snails (N) }\end{array}$ & $\begin{array}{c}\text { Prevalence of Neorickettsia }=\% \\
\text { among snails infected } \\
\text { with digeneans (N) }\end{array}$ \\
\hline Pond 1 & $9 \%(100)$ & $11 \%(9)$ \\
Pond 2 & $25 \%(187)$ & $23 \%(47)$ \\
Pond 3 & $56 \%(329)$ & $3 \%(184)$ \\
Total & $39 \%(616)$ & $8 \%(240)$ \\
\hline
\end{tabular}


Table 2 Prevalence of Neorickettsia infection among individual cercariae and sporocysts parasitizing snails, Nelson Co., North Dakota

\begin{tabular}{lcc}
\hline Digenean species & Life cycle stage & \% positive (N) \\
\hline Plagiorchis elegans & Cercariae & $11 \%(100)$ \\
Plagiorchis elegans & Cercariae & $52 \%(100)$ \\
Plagiorchis elegans & Cercariae & $70 \%(50)$ \\
Plagiorchis elegans & Cercariae & $91 \%(100)$ \\
Plagiorchis elegans & Cercariae* & $90 \%(50)$ \\
Plagiorchis elegans & Sporocysts* & $100 \%(50)$ \\
\hline *
\end{tabular}

$N$. risticii, but only $90 \%$ of cercariae from the same snail had neorickettsial infection (Table 2; $\mathrm{X}^{2}$ with Yates correction $=3.37, \mathrm{df}=1, \mathrm{p}=0.07$ ).

\section{Discussion}

Transmission of Neorickettsia through the complex digenean life cycle does not fit easily into the classical categories of vertical transmission. Due to the presence of both sexual and asexual stages in digenean life cycles it is clear that the vertical transmission of Neorickettsia through the digenean life cycle is not wholly dependent on transovarian transmission as in the case of some other bacterial pathogens/symbionts of invertebrates.

Although all 3 ponds surveyed in the study area produced some snails harboring Neorickettsia-infected digeneans (Table 1), the prevalence of Neorickettsia infection between ponds differed dramatically, from only $3.3 \%$ in Pond 3 to $23.4 \%$ in Pond 2. At the same time, the highest prevalence of digenean infections in snails was in Pond 3, reaching 56\% vs $25 \%$ in Pond 2 (Table 1 ). This illustrates the highly heterogenous nature of $N$. risticii distribution within a landscape and has certain implications for the epidemiology of Potomac horse fever caused by this bacterial species.

It is noteworthy that both low and high prevalences of neorickettsial infections of individual cercaria were found in the same parasite species ( $P$. elegans), the same snail species (L. stagnalis), and the same body of water (Pond 2; Table 2). Thus, the observed differences in neorickettsial prevalence in single cercariae were not correlated with the digenean host, snail host, or locality. Overall, our data suggest that there is a lot of inherent variability in the efficiency of vertical transmission of

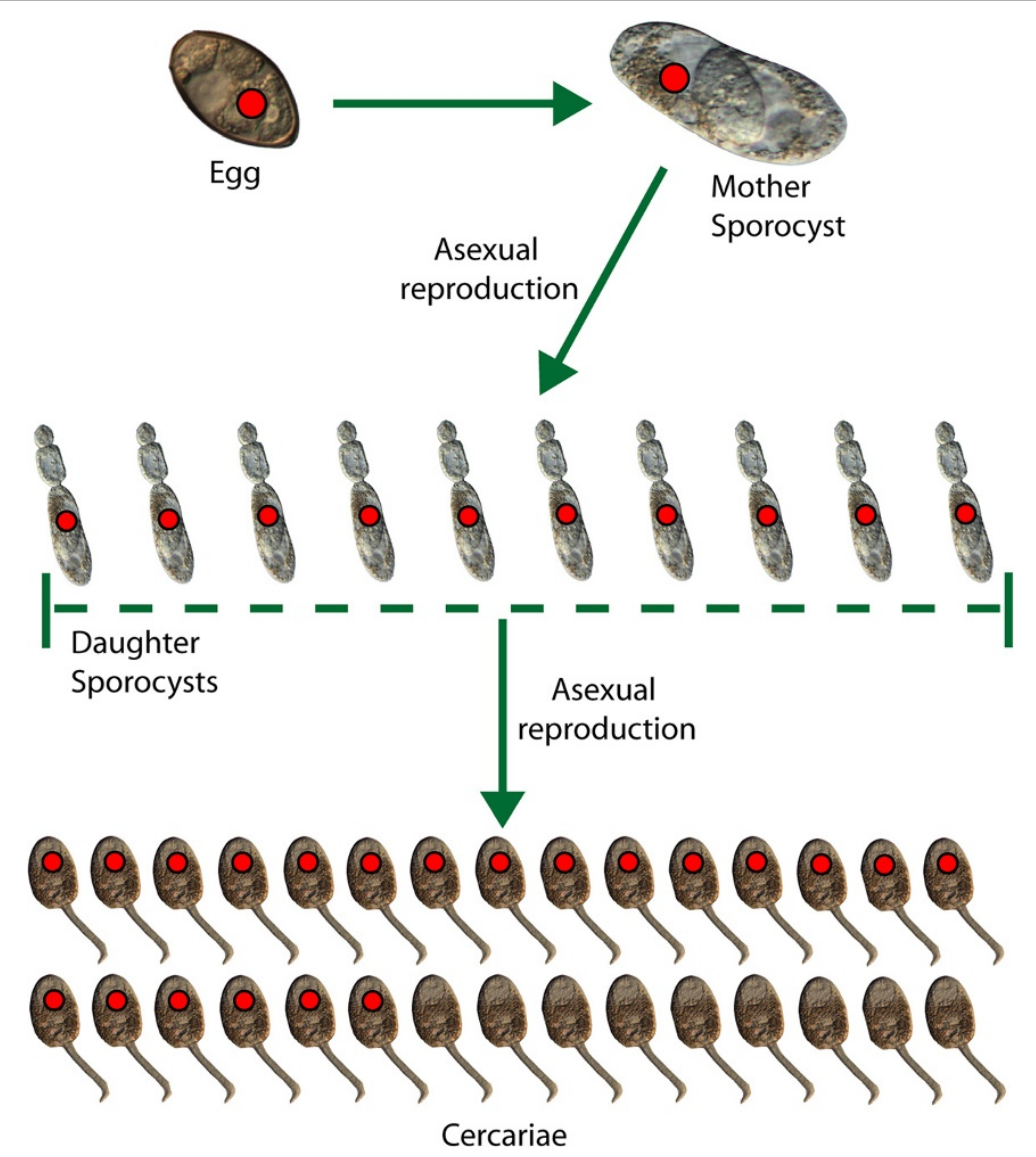

Figure 3 Transmission efficiency of Neorickettsia through asexual stages of $P$. elegans life cycle. Infection with Neorickettsia is represented by a red dot. 
Neorickettsia during asexual reproduction of digeneans. The reasons for this variability are currently unknown and may depend on a number of factors. Some of the possible explanations are provided below.

Our data on the prevalence of neorickettsial infection in sporocysts and their cercarial progeny from the same snail (Table 2) indicate that most, but not all, progeny produced by an infected sporocyst inherit the bacterial endosymbiont (Figure 3). Perhaps, the initial intensity of Neorickettsia infection in egg and/or sporocyst may determine the proportion of cercarial progeny inheriting neorickettsial endosymbionts. For example, a sporocyst infected with high bacterial load may transmit Neorickettsia to a larger proportion of its cercarial progeny than a sporocyst with fewer bacteriae. This "dosage effect" would be similar to what has been described in the transovarial infection of ticks with Rickettsia rickettsii. Female ticks with high intensity of infection transmitted rickettsiae to $100 \%$ of their progeny, while those with mild infections produced considerably lower percentages of infected eggs [29].

Alternatively, the rate of neorickettsial replication may be slower than the rate of development and replication of digenean asexual stages. If true, this asynchrony could result in a lower Neorickettsia prevalence in cercariae produced by snails that have only recently begun shedding compared to snails with older digenean infection.

Transmission in the digenean-Neorickettsia system is different from that of the other members of the family Anaplasmataceae symbiotic with invertebrates. The Anaplasmataceae includes 3 or 4 (depending on the systematic views of different authors) other genera associated with either ticks or other arthropods (Ehrlichia, Anaplasma, Wolbachia) or filarial nematodes (Wolbachia). In the case of Ehrlichia and Anaplasma, vertical transmission plays little role in their circulation $[5,30]$. In contrast, Wolbachia infects the ovaries and other tissues of many species of arthropods and filarial nematodes and is transmitted exclusively by vertical transmission [31-33]. Thus, Neorickettsia are unique among the members of the family because it can be transmitted both vertically and horizontally. In this respect, the patterns of transmission exhibited by Neorickettsia are more similar to those observed among pathogenic spotted fever group Rickettsia (e.g., $R$. rickettsii, family Rickettsiaceae, order Rickettsiales) [34].

Like Neorickettsia, Wolbachia is maintained through vertical transmission, however, there are key differences between the 2 genera of bacteria. Wolbachia and the filariae have a mutualistic relationship [35-37]. Ferri et al. [32] supposed that the bacteria may be essential to the biosynthesis of some molecules necessary for filarial host fertility and viability, such as heme, riboflavin or nucleotide synthesis. As a result, filarial species that host Wolbachia, are dependent on the presence of these endosymbionts. Landmann et al. [33] showed that filarial nematodes infected with Wolbachia pass it on to $100 \%$ of eggs. The exact nature of the interrelationships between Neorickettsia and their digenean hosts is not known. Currently, there is no evidence suggesting a mutualistic relationship between digeneans and Neorickettsia. In our study, the majority of $P$. elegans did not harbor Neorickettsia, which proves that these digeneans are not dependent on their neorickettsial endosymbionts. Presently available data are insufficient to classify the endosymbiotic relationships of Neorickettsia with digeneans as either parasitic or commensal.

\section{Conclusions}

Our data demonstrate that the transmission efficiency of Neorickettsia through asexual stages of the P. elegans life cycle is lower than $100 \%$ (Figure 3). In cercariae from naturally infected snails, the prevalence of Neorickettsia ranged from 11 to $91 \%$. Even in a case where $100 \%$ of screened daughter sporocysts harbored Neorickettsia, only $90 \%$ of the cercarial progeny were infected. These findings are in contrast with the situation in some other bacterial endosymbionts, such as Wolbachia in Wolbachia-dependent filariid nematodes, where the vertical transmission rates are $100 \%$.

\section{Competing interests}

The authors declare that they have no competing interests.

\section{Authors' contributions}

SEG participated in study design, collected snails, analyzed the data, carried out experiments, created figures, and drafted the manuscript. WT participated in study design, collected snails, analyzed the data, and helped draft the manuscript. JAV participated in study design, analyzed the data, and helped draft the manuscript. All authors read and approved the final version of the manuscript.

\section{Acknowledgements}

We are thankful to Maksym Tkach, Kayla Steffes and Christopher Bothun for their help with snail collecting, screening and husbandry. We also thank Dr. John Madigan (University of California Davis) for kindly providing us with positive control for our PCR reactions and Dr. Robert Newman for proof reading the manuscript. Lastly, we thank Charles Lentz for allowing us to use his muskrat picture in Figure 1. This work was supported in part by the grant R15Al092622 from the National Institutes of Health, USA. Collecting and screening of snails for cercariae was supported by the grant DEB 1021431 from the National Science Foundation, USA.

Received: 30 August 2013 Accepted: 30 September 2013 Published: 22 October 2013

\section{References}

1. Rikihisa Y: The tribe Ehrlichia and ehrlichial diseases. Clin Microbiol Rev 1991, 4:286-308.

2. Walker DH, Dumler JS: Emergence of the ehrlichioses as human health problems. Emerg Infect Dis 1996, 2:18-29.

3. Madigan JE, Pusterla N: Ehrlichial diseases. Vet Clin North Am Equine Pract 2000, 16:487-499.

4. Newton P, Rolain JM, Rasachack B, Mayxay M, Vathanatham K, Seng P, Phetsouvanh R, Thammavong T, Zahidi J, Suputtamongkol Y, Syhavong B, Raoult D: Sennetsu neorickettsiosis: a probable fish-borne cause of fever rediscovered in Laos. Am J Trop Med Hyg 2009, 81:190-194.

5. Headley SA, Scorpio DG, Vidotto O, Dumler JS: Neorickettsia helminthoeca and salmon poisoning disease: a review. Vet J 2011, 187:165-173. 
6. Vaughan JA, Tkach W, Greiman SE: Neorickettsial endosymbionts of the Digenea: diversity, transmission and distribution. Adv Parasitol 2012, 79:253-297.

7. Tkach W, Schroeder JA, Greiman SE, Vaughan JA: New genetic lineages, host associations and circulation pathways of Neorickettsia endosymbionts of digeneans. Acta Parasitol 2012, 57:285-292.

8. Holland CJ, Ristic M, Cole Al, Johnson P, Barker G, Goetz T: Isolation, experimental transmission, and characterization of causative agent of Potomac horse fever. Sci 1985, 227:522-524.

9. Holland CJ, Ristic M, Huxsoll DL, Cole Al, Rapmund G: Adaptation of Ehrlichia sennetsu to canine blood monocytes: preliminary structural and serological studies with cell culture-derived Ehrlichia sennetsu. Infect Immun 1985, 48:366-371.

10. Holland CJ, Weiss E, Burgdorfer W, Cole Al, Kakoma I: Ehrlichia risticii sp. nov.: etiological agent of equine monocytic ehrlichiosis (synonym, Potomac horse fever). Int J Syst Bacterio/ 1985, 35:524-526.

11. Rikihisa Y, Perry BD: Causative ehrlichial organisms in Potomac horse fever. Infect Immun 1985, 49:513-517.

12. Coffman EA, Abd-Eldaim M, Craig LE: Abortion in a horse following Neorickettsia risticii infection. J Vet Diagn Invest 2008, 20:827-830.

13. Long MT, Goetz TE, Whiteley HE, Kakoma I, Lock TE: Identification of Ehrlichia risticii as the causative agent of two equine abortions following natural maternal infection. J Vet Diagn Invest 1995, 7:201-205.

14. Barlough JE, Reubel GH, Madigan JE, Vredevoe LK, Miller PE, Rikihisa Y: Detection of Ehrlichia risticii, the agent of Potomac horse fever, in freshwater stream snails Pleuroceridae Juga spp. of Northern California. J Appl Environ Microbiol 1998, 64:2888-2893.

15. Reubel GH, Barlough JE, Madigan JE: Production and characterization of Ehrlichia risticii, the agent of Potomac horse fever, from snails (Pleuroceridae: Juga spp.) in aquarium culture and genetic comparison to equine strains. J Clin Microbiol 1998, 36:1501-1511.

16. Dumler JS: Bugs, snails and horses: expanding the knowledge of infection vectors with new and old technologies. Equine Vet $J 2000$, 32:273-274.

17. Pusterla N, Madigan JE, Chae JS, Derock E, Jonson E, Pusterla JB: Helminthic transmission and isolation of Ehrlichia risticii, the causative agent of Potomac horse fever, by using trematode stages from freshwater stream snails. J Clin Microbiol 2000, 38:1293-1297.

18. Pusterla N, Johnson E, Chae JS, Pusterla JB, DeRock E, Madigan JE: Infection rate of Ehrlichia risticii, the agent of Potomac horse fever, in freshwater stream snails (Juga yrekaensis) from northern California. Vet Parasitol 2000, 92:151-156.

19. Pusterla N, Johnson EM, Chae JS, Madigan JE: Digenetic trematodes, Acanthatrium sp. and Lecithodendrium sp., as vectors of Neorickettsia risticii, the agent of Potomac horse fever. J Helminthol 2003, 77:335-339.

20. Chae JS, Pusterla N, Johnson E, Derock E, Lawler PE, Madigan EJ: Infection of aquatic insects with trematode metacercariae carrying Ehrlichia risticii, the cause of Potomac horse fever. J Med Entomol 2000, 37:619-625.

21. Chae JS, Kim MS, Madigan J: Detection of Neorickettsia (Ehrlichia) risticii in tissues of mice experimentally infected with cercariae of trematodes by in situ hybridization. Vet Microbiol 2002, 88:233-243.

22. Mott J, Muramatsu Y, Seaton E, Martin C, Reed S, Rikihisa Y: Molecular analysis of Ehrlichia risticii in adult aquatic insects in Pennsylvania, in horses infected by ingestion of insects, and isolated in cell culture. J Clin Microbiol 2002, 40:690-693.

23. Gibson KE, Rikihisa Y, Zhang C, Martin C: Neorickettsia risticii is vertically transmitted in the trematode Acanthatrium oregonense and horizontally transmitted to bats. Environ Microbiol 2005, 7:203-212.

24. Gibson KE, Rikihisa Y: Molecular link of different stages of the trematode host of Neorickettsia risticii to Acanthatrium oregonense. Environ Microbiol 2008, 10:2064-2073.

25. Park BK, Kim MJ, Kim EH, Kim MS, Na DG, Chae JS: Identification of trematode cercariae carrying Neorickettsia risticii in freshwater stream snails. Ann N Y Acad Sci 2003, 990:239-247.

26. Farren L: Potomac horse fever: the final piece of the puzzle. EQUUS 2007, 357:49-58.

27. Tkach W, Pawlowski J: A new method of DNA extraction from the ethanol-fixed parasitic worms. Acta Parasitol 1999, 44:147-148.

28. Barlough JE, Rikihisa Y, Madigan JE: Nested polymerase chain reaction for detection of Ehrlichia risticii genomic DNA in infected horses. Vet Parasitol 1997, 68:367-373.
29. Burgdorfer W, Brinton LP: Mechanisms of transovarial infection of spotted fever rickettsiae in ticks. Ann NY Acad Sci 1975, 266:61-72.

30. Dumler JS, Barbet AF, Bekker CPJ, Dasch GA, Palmer GH, Ray SC, Rikihisa Y, Rurangirwa FR: Reorganization of genera in the families Rickettsiaceae and Anaplasmataceae in the order Rickettsiales: unification of some species of Ehrlichia with Anaplasma, Cowdria with Ehrlichia and Ehrlichia with Neorickettsia, descriptions of six new species combinations and designation of Ehrlichia equi and 'HE agent' as subjective synonyms of Ehrlichia phagocytophila. Int J Syst Evol Microbiol 2001, 51:2145-2165.

31. Werren JH, Zhang W, Guo LR: Evolution and phylogeny of Wolbachia: reproductive parasites of arthropods. Proc R SOC B 1995, 261:55-63.

32. Ferri E, Bain O, Barbuto M, Martin C, Lo N, Uni S, Landmann F, Baccei SG, Guerrero R, de Souza Lima S, Bandi C, Wanji S, Diagne M, Casiraghi M: New insights into the evolution of Wolbachia infections in filarial nematodes inferred from a large range of screened species. PLoS One 2011, 6:e20843.

33. Landmann F, Bain O, Martin C, Uni S, Taylor MJ, Sullivan W: Both asymetric mitotic segregation and cell-to-cell invasion are required for stable germline transmission of Wolbachia in filarial nematodes. Biol Open 2012, 1:536-547.

34. Schriefer ME, Azad AF: Ecology and natural history of Rickettsia rickettsii. In Ecological dynamics of tick-borne zoonoses. Edited by Sonenshine DE, Mather TN. New York, NY: Oxford University Press; 1994:314-326.

35. Taylor MJ, Bandi C, Hoerauf A: Wolbachia pipientis bacterial endosymbionts of filarial nematodes. Adv Parasitol 2005, 60:245-284.

36. Bordenstein SR, Paraskevopoulos C, Hotopp JCD, Sapountzis P, Lo N, Bandi $\mathrm{D}$, Tettelin $\mathrm{H}$, Werren $\mathrm{JH}$, Bourtzis K: Parasitism and mutualism in Wolbachia: what the phylogenomic trees can and cannot say. Mol Biol Evol 2009, 26:231-241.

37. Albers A, Esum ME, Tendongfor N, Enyong P, Klarmann U, Wanji S, Hoerauf A, Pfarr K: Retarded Onchocerca volvulus L1 to L3 larval development in the Simulium damnosum vector after anti-wolbachial treatment of the human host. Parasit Vectors 2012, 5:12.

doi:10.1186/1756-3305-6-303

Cite this article as: Greiman et al:: Transmission rates of the bacterial endosymbiont, Neorickettsia risticii, during the asexual reproduction phase of its digenean host, Plagiorchis elegans, within naturally infected lymnaeid snails. Parasites \& Vectors 2013 6:303.

\section{Submit your next manuscript to BioMed Central and take full advantage of:}

- Convenient online submission

- Thorough peer review

- No space constraints or color figure charges

- Immediate publication on acceptance

- Inclusion in PubMed, CAS, Scopus and Google Scholar

- Research which is freely available for redistribution 